CASTELO BRANCO, M.; PONTES, L.A.; AMARAL, P.S.T.; MESQUITA FILHO, M.V.. Inseticidas para o controle da traça-do-tomateiro e broca-grande e seu impacto sobre Trichogramma pretiosum. Horticultura Brasileira, Brasília, v. 21, p. 652-654, outubro-dezembro 2003.

\title{
Inseticidas para o controle da traça-do-tomateiro e broca-grande e seu impacto sobre Trichogramma pretiosum
}

\author{
Marina Castelo Branco; Ludimilla A. Pontes; Pablo S.T. Amaral; Manoel V. Mesquita Filho \\ Embrapa Hortaliças, C. Postal 218, 70359-970, Brasília-DF; E-mail: marina@cnph.embrapa.br
}

\begin{abstract}
RESUMO
Experimentos de campo foram conduzidos entre maio e outubro de 2000 para determinar a eficiência de diversos inseticidas para o controle de Tuta absoluta e Helicoverpa zea e o impacto desses produtos sobre a emergência do parasitóide Trichogramma pretiosum. Os inseticidas testados, bem como as doses em g i.a./ha foram: metoxifenozide $(120 ; 144)$, clorpirifós $(540 ; 675)$, tiacloprid $(72$; 96) e triflumuron (144). O delineamento experimental foi de blocos ao acaso com oito tratamentos (inseticidas e testemunha) e cinco repetições, com 40 plantas/parcela. Frutos de tomate foram coletados aos 58,80 e 87 dias após o transplante das mudas para a determinação da percentagem de frutos danificados pelos insetos. O impacto dos inseticidas sobre T. pretiosum foi avaliado mediante a coleta de 20 ovos de H. zea por parcela aos 61 dias após o transplante, onde foi realizada a avaliação da emergência do parasitóide. Todos os inseticidas reduziram significativamente os danos causados por $H$. $z e a$. Contudo, nenhum deles foi eficiente para o controle de T. absoluta. Metoxifenozide e clorpirifós (540) não reduziram significativamente o número de ovos parasitados por T. pretiosum quando comparados à testemunha.
\end{abstract}

Palavras-chave: Tuta absoluta, Helicoverpa zea, Lycopersicon esculentum, controle químico, controle biológico, seletividade.

\begin{abstract}
Insecticides for the control of the South American tomato pinworm and the corn earworm and impact of those products on Trichogramma pretiosum
\end{abstract}

Field studies were conducted from May to October 2000 to determine the effectiveness of several insecticides in controlling Tuta absoluta and Helicoverpa zea and their impact on emergence of the parasitoid Trichogramma pretiosum. The insecticides tested were: methoxyfenozide $(120 ; 144)$, clorpirifós $(540 ; 675)$, tiacloprid (72; 96) and triflumuron (144). Application rates of all insecticides are expressed as g a.i./ha. The experiment was designed as randomized complete block with eight treatments (insecticides and untreated plots) with five replications. Tomato fruits were harvested 58; 80 and 87 days after transplanting and the percentage of damaged fruits by both pests determined. The impact of insecticides on T. pretiosum survival was determined collecting 20 eggs of $\mathrm{H}$. zea/plot 61 days after transplanting and the percentage of emerged parasitoid determined. All insecticides reduced significantly the damage caused by $H$. zea whereas none of the products were effective in controlling T. absoluta. Methoxyfenozide and clorpirifós (540) did not reduce significantly the number of eggs parasitized by $T$. pretiosum when comparared with untreated ones.

Keywords: Tuta absoluta, Helicoverpa zea, Lycopersicon esculentum, chemical control, biological control, selectivity.

\section{(Recebido para publicação em 9 de outubro de 2002 e aceito em 24 de setembro de 2003)}

A cultura do tomateiro é atacada por várias pragas, dentre elas, a traçado-tomateiro (Tuta absoluta), considerada a mais importante. As larvas minam as folhas e perfuram os frutos, tornando-os imprestáveis para o consumo. Para reduzir os danos do inseto, os inseticidas constituem a forma de controle mais utilizada, razão pela qual diversos produtos, pertencentes a diferentes grupos químicos estão registrados para uso na cultura (França et al. 2000).

A broca-grande (Helicoverpa zea) é outra praga do tomateiro. $\mathrm{Na}$ ausência de aplicações de agrotóxicos, o inseto pode causar perdas de até $80 \%$ da produção, devido à destruição da polpa do tomate (Anônimo 1969; França et al. 2000). No entanto, a broca-grande possui, atualmente, pouca importância econômica já que os inseticidas usados para o controle da traça-do-tomateiro normalmente controlam esse inseto.

Aplicações constantes de inseticidas para o controle de pragas nessa cultura causam diversos problemas, como a seleção de populações de traça-do-tomateiro resistentes aos produtos utilizados (Siqueira et al., 2000), a alteração do comportamento de inimigos naturais (Delpuech et al., 1999) além de problemas ambientais. Por essa razão, medidas que viabilizem a redução da aplicação desses produtos nas lavouras devem ser implementadas. Uma destas seria o uso de inseticidas seletivos para a manutenção de inimigos naturais das pragas.

Trichogramma pretiosum é um parasitóide de ovo, que, em associação com Bacillus thuringiensis tem reduzido significativamente os danos da traça-do-tomateiro e pode ser empregado também para o controle da broca-grande (Haji et al. 1995 e 1998; Villas Bôas \& França, 1996). Este trabalho teve por objetivo avaliar a eficiência de inseticidas para o controle de T. absoluta e $H$. $z e a$, bem como o impacto destes sobre T. pretiosum.

\section{MATERIAL E MÉTODOS}

O experimento foi realizado de maio a outubro de 2000 em um Latossolo Vermelho Escuro Distrófico (LVd) na Área Experimental da Embrapa Hortaliças em Brasília, o qual foi corrigido e fertilizado para a cultura do tomateiro conforme recomendações da EMATERDF (1987). A cultivar utilizada foi Santa Clara, a mais comum para a produção de tomate de mesa na região.

As pulverizações de inseticidas, num 
Tabela 1. Percentagem de ovos de broca grande parasitados por Trichogramma pretiosum. Coleta 61 dias após o transplante. Brasília, Embrapa Hortaliças, 2000.

\begin{tabular}{lccc}
\hline \multicolumn{1}{c}{ Tratamento } & Dose (ml/ha) & Ovos coletados & $\begin{array}{c}\text { \% ovos parasitados } \\
\text { (média } \pm \text { EPM) }\end{array}$ \\
\hline Testemunha & - & 97 & $70,4 \pm 5,7 \mathrm{a}$ \\
Methoxyfenozide & 120 & 102 & $64,3 \pm 6,4 \mathrm{a}$ \\
Methoxyfenozide & 144 & 104 & $67,6 \pm 4,7 \mathrm{a}$ \\
Clorpirifós & 540 & 94 & $62,4 \pm 5,9 \mathrm{ab}$ \\
Tiacloprid & 72 & 92 & $47,3 \pm 3,7 \mathrm{bc}$ \\
Clorpirifós & 675 & 100 & $46,3 \pm 4,9 \mathrm{c}$ \\
Tiacloprid & 96 & 90 & $43,1 \pm 7,1 \quad \mathrm{~cd}$ \\
Triflumuron & 144 & 88 & $28,4 \pm 5,9 \mathrm{~d}$ \\
\hline CV (\%) & & & $15,3 \mathrm{C}$ \\
\hline
\end{tabular}

${ }^{1 /}$ Médias seguidas pela mesma letra não diferem entre si pelo teste DMS $(\mathrm{p}>0,05)$

total de 13 , foram semanais e iniciadas uma semana após o transplante. A água utilizada para a aplicação dos inseticidas possuía $\mathrm{pH}$ original em torno de 7,07,2 . Este foi corrigido para 5,0-5,2, mediante diluição de 7,5 ml de HCL 10,5 mol L L para 100 litros de água, por ser este o $\mathrm{pH}$ ideal para a obtenção da maior eficiência dos inseticidas. Para as aplicações de inseticidas foi utilizado um pulverizador costal com capacidade de quatro litros de água. A quantidade de água consumida por hectare foi calculada a cada 15 dias e nas condições do experimento variou de 277 a 810 litros ha-1.

Foram testados os seguintes inseticidas (g.i.a. ha ${ }^{-1}$ ): metoxifenozide (120; $144)$, clorpirifós $(540 ; 675)$, tiacloprid $(72 ; 96)$ e triflumuron (144). Utilizouse também uma testemunha sem aplicação de inseticidas. O delineamento empregado foi o de blocos ao acaso, com cinco repetições e 40 plantas por parcela. $\mathrm{O}$ espaçamento empregado foi $1 \mathrm{~m}$ entre linhas e $50 \mathrm{~cm}$ entre plantas.

Para a avaliação dos danos ocasionados pela broca-grande e traça-do-tomateiro, frutos de tomate foram coletados aos 58; 80 e 87 dias após o transplante e determinada a percentagem de frutos danificados pelos insetos.

A percentagem de parasitismo de ovos de broca-grande por T. pretiosum foi determinada através da coleta de cerca de 20 ovos da praga por parcela 61 dias após o transplante. No laboratório, os ovos foram colocados individualmen-

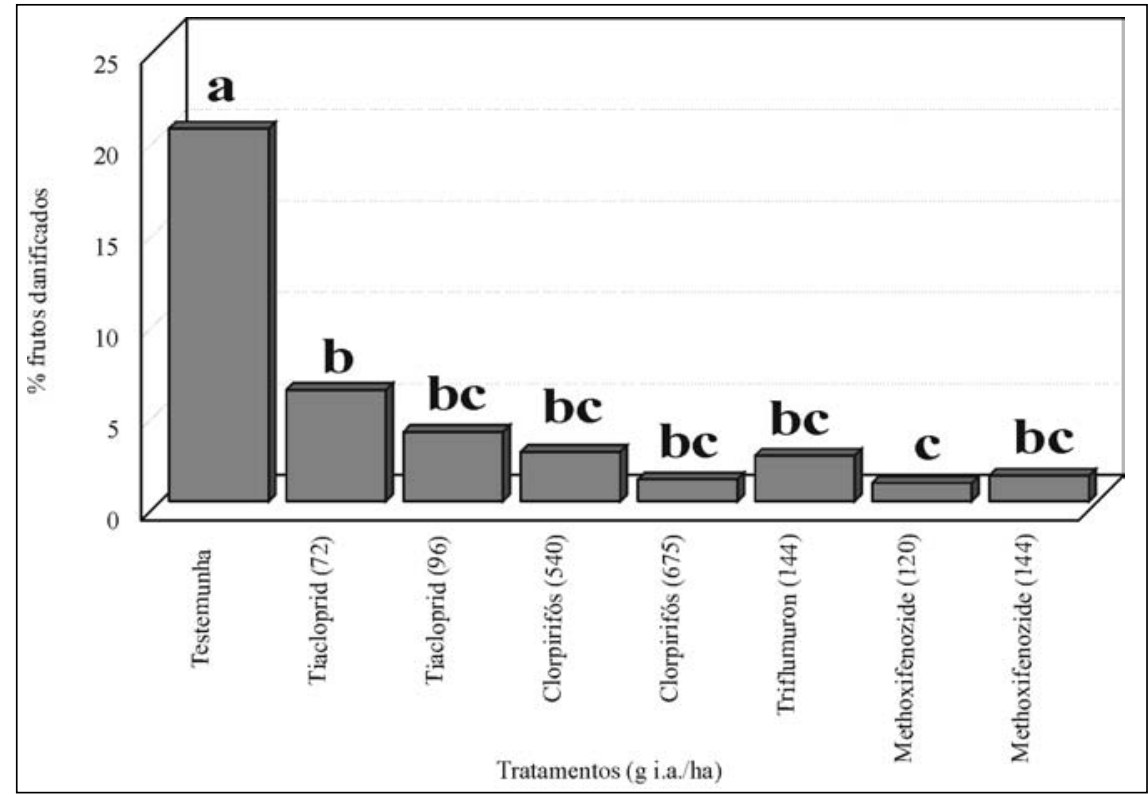

Figura 1. Percentagem de frutos de tomate danificados por broca grande após o tratamento das plantas com diferentes inseticidas. Médias seguidas de mesma letra não diferem entre si pelo teste da Diferença Mínima Significativa (p>0,05). Brasília, Embrapa Hortaliças, 2000.

te em cápsulas de gelatina e após 11 dias foi avaliada a emergência de parasitóides.

Os dados obtidos foram submetidos à análise de variância e utilizou-se o teste da Diferença Mínima Significativa (DMS) a $5 \%$ de probabilidade para a separação de médias.

\section{RESULTADOS E DISCUSSÃO}

Nenhum dos inseticidas testados foi eficiente para reduzir os danos causados pela traça-do-tomateiro. A percen- tagem de frutos brocados no tratamento testemunha foi de $33 \%$, enquanto que para os tratamentos com inseticida esta percentagem variou de $31 \%$ (metoxifenozide, 144) a $54 \%$ (clorpirifós, 675). As causas destes resultados podem ser várias, dentre elas: a) resistência da praga aos inseticidas utilizados. No Distrito Federal foi observado que as doses comerciais de fosforados e reguladores de crescimento não controlavam o inseto (Castelo Branco et al. 2001); b) falta de ação translaminar dos inseticidas. As larvas de traça-do-tomateiro se situam no in- 
terior das minas formadas por elas em folhas de tomateiro, e alguns dos produtos testados podem não atingir o inseto. Tal problema foi observado com cartap, inseticida tradicionalmente utilizado para o controle da traça-do-tomateiro. Larvas da praga colocadas sobre folhas de tomate apresentaram maior percentual de mortalidade do que larvas localizadas no interior das minas (Castelo Branco et al., 1996).

Todos os inseticidas testados foram eficientes para reduzir os danos de broca-grande (Figura 1). A eficiência dos inseticidas para o controle desta praga pode ser explicada pelo fato de as larvas ficarem expostas no ambiente e assim poderem ser facilmente atingidas pelas aplicações de agroquímicos.

O parasitóide T. pretiosum foi encontrado parasitando $70 \%$ dos ovos de broca-grande no tratamento testemunha (Tabela 1). No entanto, ainda que o parasitismo natural tenha alcançado esse índice, observou-se que $20 \%$ dos frutos foram danificados por broca-grande (Figura 1), donde infere-se que a população do inimigo natural não foi suficiente para reduzir os danos causados pelo inseto. O nível de ação para esta praga, estabelecido por Groppo et al. (1999), foi de quatro ovos/100 folhas. Neste trabalho, ainda que o número de folhas coletadas para a obtenção dos cerca de 20 ovos por parcela não tenha sido determinado, com certeza foram amostradas menos de 100 folhas. Com isto, o número de ovos nas parcelas testemunhas era muito superior ao nível de ação proposto, ou seja, inseticidas deveriam ter sido empregados.

Metoxifenozide, nas duas dosagens, não reduziu significativamente a emergência de $T$. pretiosum (Tabela 1). Resultado semelhante foi obtido por Suil et al. (2000), que observaram também que quando o parasitóide foi tratado como larva, pré-pupa ou pupa com o inseticida, a sua longevidade não foi afetada. No que se refere ao inseticida clorpirifós, a menor dosagem (540 g.i.a./ ha) também não afetou a percentagem de parasitismo. Os resultados aqui obtidos são diferentes do observado por
Hohmann (1993), que verificou que, em testes de laboratório, a dose de 400 g.i.a./ ha de clorpirifós reduziu a emergência do parasitóide.

Tiacloprid e triflumuron reduziram significativamente a percentagem de ovos de broca-grande parasitados por $T$. pretiosum, não sendo aparentemente indicados para uso em áreas onde se deseje implementar a associação inseticida-parasitóide. Deve ser ressaltado que tiacloprid é um produto eficiente para o controle de mosca-branca em tomate (Castelo Branco \& Pontes, 2001). Assim sendo, em áreas onde o parasitóide esteja sendo liberado para o controle da traça-do-tomateiro, a aplicação de tiacloprid para o controle de mosca-branca deve levar em conta o impacto deste produto sobre o parasitóide. O resultado obtido com triflumuron está de acordo com as observações de Carvalho et al. (1994) e Narayana \& Babu (1992), os quais verificaram que o inseticida, ao reduzir o desenvolvimento larval de $T$. pretiosum e T. chilonis, diminuiu em ambos a percentagem de emergência.

Em resumo, nas condições deste trabalho, verificou-se que nenhum dos inseticidas testados foi eficiente para o controle da traça-do-tomateiro, embora todos eles tenham sido eficientes para o controle da broca-grande. Os inseticidas metoxifenozide e clorpirifós na menor dosagem não afetaram o índice de parasitismo de ovos de broca-grande por $T$. pretiosum.

\section{AGRADECIMENTOS}

A Hozanan P. Chaves pelo auxílio nos trabalhos de campo e laboratório.

\section{LITERATURA CITADA}

ANÔNIMO. Brocas podem destruir em pouco tempo toda uma plantação de tomate. Agricultura e Pecuária, São Paulo, n. 538, p. 36-37, 1969. CARVALHO, G.A.; TIRONI, P.; RIGITANO, R.L.O.; SALGADO, L.O. Seletividade de inseticidas reguladores de crescimento de insetos a Trichogramma pretiosum Riley (Hymenoptera: Trichogrammatidae). Anais da Sociedade Entomológica do Brasil, Londrina, v. 23, p. 431434, 1994.
CASTELO BRANCO, M.; PONTES, L.A. Avaliação da eficiência de tiacloprid para o controle de mosca-branca. Horticultura Brasileira, v. 19, p. 97-101. 2001

CASTELO BRANCO, M.; FRANÇA, F.H.; FON-

TES, R.R. Eficiência relativa de inseticidas em mistura com óleo mineral sobre o nível de dano econômico da traça-do-tomateiro. Horticultura Brasileira, Brasília, v. 14, p. 36-38, 1996.

DELPUECH, J.M.; GAREAU, E.; FROMENT, B.; ALLEMAND, R.; BOULETREAU, M. Effets de differentes doses d'un insecticide sur la communication par pheromones sexuelles du trichogramme, Trichogramma brassicae Bezdenko (Hymenoptera: Trichogrammatidae). Annales de la Societe Entomologique de France, v. 35 (Supp), p. 514-516, 1999.

EMATER-DF Recomendações para o uso de corretivos, matéria orgânica e fertilizantes para hortaliças no Distrito Federal; $1^{\circ}$ aproximação. Brasília: EMATER-DF/EMBRAPA-CNPH, 1987. 50 p.

FRANÇA, F.H.; VILLAS BôAS, G.L.; CASTELO BRANCO, M.; MEDEIROS, M.A. Manejo integrado de pragas Organizado por: Silva J.B.C.; Giordano L.B. Tomate para processamento industrial, Brasília, Embrapa SPI, 2000, p. 112-127.

GROPPO, G.A.; GRAVENA, S.; LEITE, D. Manejo integrado de pragas (MIP) na cultura de tomate estaqueado. In: ENCONTRO PARA DIVULGACAO DE EXPERIENCIAS CATI, 1998, Campinas, SP. Anais... Campinas: CATI, 1999. p.1-3.

HAJI, F.N.P.; FREIRE, L.C.L.; ROA, F.G.; SILVA, C.N.; SOUZA JUNIOR, M.M.; SILVA, M.I.V. Manejo integrado de Scrobipalpuloides $a b$ soluta (Polvony) (Lepidoptera: Gelechiidae) no Submédio São Francisco. Anais da Sociedade Entomológica do Brasil, Londrina, v. 24, n. 3, p. 587-591, 1995.

HAJI, F.N.P.; ALENCAR, J.A.; PREZOTTI, L. Principais pragas do tomateiro e alternativas de controle. Petrolina: EMBRAPA-CPATSA, 1998. 50 p.

HOHMANN, C.L. Efeito de alguns inseticidas sobre adultos de Trichogramma pretiosum Riley. Anais da Sociedade Entomológica do Brasil, Londrina, v. 22, p. 563-568. 1993.

NARAYANA, M.L.; BABU, T.R. Evaluation of five insect growth regulators on the egg parasitoid Trichogramma chilonis (Ishii) (Hym., Trichogrammatidae) and the hatchability of Corcyra cephalonica Staint (Lep., Galleriidae). Journal of Applied Entomology, v. 113, p. 56-60,1992.

SIQUEIRA, H.A.A., GUEDES, R.N.C.; PICANÇO, M.C. Insecticide resistance in populations of Tuta absoluta (Lepidoptera: Gelechiidae). Agricultural and Forest Entomology, v. 2, p. 147-153, 2000.

SUIL, C.P.C.; ORR, D.B.; van DUYN, J.W. Effect of insecticides on Trichogramma exiguum (Trichogrammatidae: Hymenoptera) preimaginal development and adult survival. Journal of Economic Entomology, v. 93, p. 577-583. 2000.

VILLAS BOAS, G.L.; FRANCA, F.H. Utilização do parasitóide Trichogramma pretiosum no controle da traça-do-tomateiro em cultivo protegido de tomate. Horticultura Brasileira, v. 14, n. 2, p. 223-225, 1996. 